\title{
The Status of Maternal and Child Health in Latin Amercan Countries and Related Policy Measures: Focusing on Teen Pregnancy Problems
}

\author{
S. H. Park
}

\begin{abstract}
Maternal and child health care is a problem to be dealt with by a country's active management, support, and international cooperation. If a mother and child health project in a country fails, the proportion of the socio-economic burden that the country will bear is quite large. In the cases of teen pregnancy and childbirth, which are related to maternal and child health, considering the fact that the prevention effect of maternal and child health is higher for younger individuals, the measures to cope with teen pregnancy and childbirth will have a positive effect on the effectiveness of the maternal and child health projects in that country. In this respect, the study of the current state of Latin American countries with serious teen pregnancy problems and measures for solving this problem is a great help for understanding the effectiveness of maternal and child health projects. The Latin American countries studied in this study were Nicaragua, Honduras, Ecuador, Guatemala, El Salvador, and the Dominican Republic, all of which have a high pregnancy rate for teens. Their common points are that women's human rights are poor, poverty is high, and the education level is low. Therefore, to solve the problem of teen pregnancy in these countries, it is necessary to improve school sex education and solve the problems of women's human rights and social support at the national policy level. Countries facing these problems need to cooperate.
\end{abstract}

Index Terms-Maternal and child health, teen pregnancy, unwed mothers, Latin America, international cooperation.

\section{INTRODUCTION}

Maternal and child health regards the health of mothers and their children, and the ultimate goal is for them to raise healthy children by maintaining normal pregnancies and safe births. Because maternal and child health targets both the mother and child, maternal and child health projects should be easily accessible to all subjects. If maternal and child health projects fail, family and social burdens will be great and difficult to bear.

In maternal and child health care, prevention rather than treatment can be an effective alternative. In particular, the effect of prevention increases for younger individuals. Therefore, interest in teen pregnancy or single mothers should be significant, and in this respect, teens are a very important subject in terms of maternal and child health.

Teen pregnancy and childbirth are also big problems in Korea, and it is safe to say that teen pregnancy and childbirth are very common problems worldwide. In particular, the problems of teen pregnancy and childbirth in Latin America, where social openness and poverty are high and

Manuscript received May 25, 2017; revised August 2, 2017.

S. H. Park is with the Hankuk Academy of Foreign Studies, South Korea (email: shever14@naver.com). physical growth and sexual maturation are relatively fast, are more serious than in Korea.

In Latin America, the rate of teen pregnancy is increasing, especially in Nicaragua, Honduras, Ecuador, Guatemala, El Salvador, and the Dominican Republic.

In the case of teen pregnancy, either abortion or childbirth is a choice, but neither is a perfect choice. Individuals usually experience deep feelings of guilt, anger, depression, victimhood, and explosive changes in emotions after an abortion. In addition, single teen mothers who choose to give birth tend to be deprived of prenatal and postpartum health care and suffer from nutritional deficiency or physical immaturity. The majority tend to conceal the pregnancy, so the prenatal consultation rate is low and various complications may occur more often than in normal pregnancies [1].

However, in countries with low levels of women's human rights, such as Latin America, post-contraception and abortion are not easy, and women can be treated as criminals and end up in prison if the abortion laws are broken. Therefore, the issue of teen pregnancy is no longer a problem of just Latin American countries, but of the international community. Thus, through this study, the status of maternal and child health in Latin American countries was analyzed in relation to the teen pregnancy problem and a solution for this problem was sought.

\section{THEORETICAL CONSIDERATIONS}

\section{A. Concepts and Characteristics of Maternal and Child Health}

Maternal and child health refers to the health of the mother and her child. Therefore, the ultimate goal of maternal and child health is for pregnant women to maintain their health, learn health and child care skills as well as possible, and raise healthy children through a normal pregnancy and safe delivery [2].

According to the World Health Organization (WHO) Maternal and Child Health Commission [3], the goal of maternal and child health is to resolve the urgent health problems of mothers and their children and ensure that women can conceive healthy children and give birth normally by maintaining their health and acquiring skills for their children's education [4].

In Korea, the Maternal and Child Health Act defines maternal and child health services. Article 2, Section VIII provides maternal and infant health care services and related information. Additionally, it helps women to maintain their physical, mental, and social health through reproductive health care and pregnancy, childbirth, and childcare support. 

ble.

The above concepts are summarized in the following ta-

TABLE I. MATERNAL AND CHILD HEALTH CONCEPTS

\begin{tabular}{|c|l|}
\hline Source & \multicolumn{2}{|c|}{ Concepts } \\
\hline $\begin{array}{c}\text { E. G. Park } \\
(2000)\end{array}$ & $\begin{array}{l}\text { Mothers-to-be and pregnant women maintain their health and learn health and } \\
\text { child care skills as well as possible and raise healthy children through normal } \\
\text { pregnancies and safe delivery }\end{array}$ \\
\hline $\begin{array}{c}\text { H. J. Kim \& S. } \\
\text { N. Yoon } \\
(1998) \\
\text { recitation }\end{array}$ & $\begin{array}{l}\text { To resolve the urgent health problems of mothers and their children and to ensure } \\
\text { that women can conceive healthy children and give birth normally by maintaining } \\
\text { their health and acquiring skills for their children's education }\end{array}$ \\
\hline $\begin{array}{c}\text { Maternal \& } \\
\text { Child Health } \\
\text { ACT }\end{array}$ & $\begin{array}{l}\text { It provides maternal and infant health care services and related information. It } \\
\text { also helps them to maintain their physical, mental, and social health through re- } \\
\text { Article 2, } \\
\text { Section 8 }\end{array}$ \\
\hline
\end{tabular}

In summary, maternal and child health can be defined as "ensuring health and safety in the pregnancy, childbirth and nursing process for the mother or pregnant woman and the child or fetus." The following definitions of terms used in the concept of maternal and child health are introduced by E. G. Park: A pregnant woman refers to a woman who is pregnant or who is less than 6 months after birth. Additionally, newborn refers to infants less than 28 days after birth and motherhood in the broad sense means women from their first menstrual period to menopause and in the narrow sense means women who are pregnant or have delivered under 6 months or less than 1 year ago.

E. G. Park insists that because maternal and child health targets mothers and children, maternal and child health programs should be easily accessible to all subjects, and all health care institutions and individuals involved in maternal and child health should share common goals and interests in their respective roles and cooperate with each other. The reason for this is that if a maternal and child health project fails, family and social burdens will be significant and difficult to bear. Therefore, we are making efforts not only in Korea, but also in other countries worldwide to ensure the success of maternal and child health projects.

In this regard, T. G. Park [5] explains that the success of mother and child health projects can be defined as follows:

First, fertile women should be able to maintain good physical and psychological health, be able to conceive a healthy child at a desired time, and acquire infant-related skills to raise a healthy child.

Second, all children should be able to grow in a healthy environment, a harmonious home, be well fed, and be protected from disease.

Third, both mothers and children should be able to avoid epidemics and acquire the knowledge and skills necessary for self-care through health education.

Fourth, disease must be discovered early and treated within the range of the mother's payment capability before it becomes severe or chronic.

Fifth, nationwide data clearly showing the level of maternal and child health and changes in the mortality and incidence rates should be collected and evaluated [5].

There is also a way to numerically identify countries with good maternal health - that is, countries with good maternal and child health outcomes. E. G. Park explains that for this purpose, the birth, stillbirth, infant mortality, maternal mortality, newborn mortality, infant mortality, perinatal mortality, infant mortality, and fertility rates are examined. In particular, these serve as indicators of the health status of a country. The reason for using this index is that pregnant women and infants who are subject to maternal and child health services are very vulnerable, and most related illnesses are easily prevented, but once they occur, they are associated with a high mortality rate, and even if they are successfully treated, they are likely to become lifelong disabilities or malformations compared with the illnesses of other age groups.

\section{B. Youth Issues from the Perspective of Maternal and Child Health}

In the narrow sense, the purposes of maternal and child health care are care for pregnant women, safe delivery, newborn care, and breastfeeding support. If any one of these fails, maternal and child health care is not properly carried out. Maternal and child health care should begin at younger ages to motivate health care behavior and prevent health problems. T. G. Park mentions that these days, counseling before marriage and sex education, including genetic counseling, are naturally included in maternal and child health care.

According to E. G. Park, in addition, the most important part of maternal and child health care is finding, registering, and starting to care for all possible pregnancies at an early stage. Risk factors can be eliminated or addressed through special education, nutrition education, etc. on precautions to take during pregnancy, while high-risk pregnant women are regularly provided with regular prenatal care.

Thus, prevention can be an effective alternative to treatment in maternal and child health care. In particular, prevention is more effective at a younger age. Pregnancy is not a morbid condition, but a normal physiological process. Problems during pregnancy are mostly preventable, but when they cannot be prevented, the consequences are very serious and it is common for newborns to be left with a lifelong disability.

Based on this evidence, youth education on maternal and child health should be an important project. In particular, pregnant teens will choose abortion or childbirth as a solution to their pregnancy, but neither is a perfect choice. Abortion can give them feelings of deep shame, guilt, anger, depression, damage consciousness, explosive changes in emotions, and stress. In addition, teen mothers who choose to give birth tend to be deprived of prenatal and postnatal health care and suffer from malnutrition or physical immaturity. H. H. Kim mentions that the majority tend to conceal the pregnancy, so the prenatal consultation rate is low and various complications can result. The possibility of this may be higher than in normal birth.

Additionally, teen mothers are more likely to experience more difficulties than adult mothers. This is because the possibility of future employment is high for them due to the suspension of studies, which affects society even more [6]. In this regard, teens are very important subjects in terms of maternal and child health, and preventive measures are more urgent than those for adults. 


\section{Prior Research and the Necessity of Research in Latin American Countries}

By considering teen issues from the perspective of maternal and child health, it can be seen that the problem concerns teen pregnancy and childbirth. Teen mothers' problems have recently emerged as social issues, and they have become issues of high social and academic interest.

Dr. No's study on teen pregnancy and childbirth in Korea found the following [7]: the causes of teen pregnancy derive from the functional deficit of the family and academic, relationship, and contraceptive failure. Furthermore, sexual intercourse with a lack of self-determination changes attitudes toward sex. These sexual experiences lead to pregnancy, and even after recognizing pregnancy, they are unable to cope with the situation appropriately and are forced to give birth and give up the child for adoption. As a result, unmarried mothers develop feelings of guilt and a negative self-perception, and they experience maternal love and regret after giving birth.

According to Jung's research [8], teen mothers are not prepared for pregnancy and childbirth. Therefore, when they realize that they are pregnant for the first time, they have a strong desire to have an abortion and suffer from mental and maternal pain. This process is a crucial moment during which their awareness about sex changes. They think that pregnancy before marriage is socially unacceptable. Therefore, positive awareness about sex and the need for sex education that can be practically applied are important for when teenagers face sexual intercourse.

As such, teen pregnancy and childbirth in Korea are big problems in society and are important parts of the maternal and child health policy. However, these problems are not unique to our country, but also common problems worldwide. In particular, the problems of teen pregnancy and childbirth in Latin America, where the culture is highly sexually open, physical growth and sexual maturation are fast, and the poverty level is high, is more serious than Korea.

When you submit your final version, after your paper has been accepted, prepare it in two-column format, including figures and tables.

\section{Status OF Youth MATERnAl AND CHILd HeAlth IN LATIN AMERICA}

\section{A. General Status of Teen Pregnancy Problems}

In developing countries worldwide, on average, 20,000 girls under the age of 18 give birth every day; this means 7.3 million girls under the age of 18 become mothers every year. An important issue here is that under the age of 15, the number is 2 million, and this trend is steadily increasing, with the number is expected to increase to 3 million by 2030 [9].

According to UNFPA, $19 \%$ of young women in developing countries are pregnant before the age of 18 and $95 \%$ of the world's teenage pregnancies occur in developing countries. Approximately 70,000 of these teenage girls are reported to have eventually died of complications from pregnancy and childbirth [10].

J. Y. Oh insists that according to Pathfinder International (1998) and Bal-arajan (2011), about 50\% of teenage girls suffering from complications from pregnancy and childbirth experience miscarriage or stillbirth, premature birth, or death due to iron deficiency (anemia). Studies on babies of these teen moms have also revealed the seriousness of teen pregnancy. In 2013, WHO also reports that the death rate of babies born by teens is $50 \%$ higher than that of babies born by mothers in their twenties. And about 1 million babies born from teenage girls don't reach the first year milestone.

Most of the societies or families in which the teen pregnancy is a problem are poor with low levels of education, and lacking a system at the national level [11]. Teen pregnancy can occur in any country with teenagers who are born in poverty-stricken families, not just in developing countries. The more serious the economic issues, the poorer the education, such as in developing countries, the more serious the problem becomes. Therefore, it is important to find out how to solve the problem of teen pregnancy by analyzing the cases of developing countries that have serious teen pregnancy problems.

\section{B. Status of Teen Pregnancy Problems in Latin American Countries}

In Latin America, which includes many developing countries, the problem of teen pregnancy is especially prevalent. J. Y. Oh's study shows that according to data reported by UNICEF, the pregnancy rate for teens aged 15 to 19 in Latin America was $18 \%$, which was $6 \%$ higher than the worldwide average of $12 \%$.

Among the Latin American countries, Nicaragua, Honduras, Venezuela, Ecuador, and Dominican Republic have the highest rates of teen pregnancy [12]. According to WHO 's report(2013), regarding maternal mortality, Guatemala has the highest rate (140 out of 100,000), followed by Ecuador (87) and El Salvador (69). Nicaragua, Honduras, Ecuador, Guatemala, El Salvador, and the Dominican Republic are among the countries in Central and South America that are considered to have a serious problem with teen pregnancy. The details of each country are as follows.

\section{1) Nicaragua}

Korea Women's Development Institute (2014) reports that Nicaragua has the highest teen pregnancy rates in Latin America. In Nicaragua, 28\% of pregnant women are under 18 years of age, and the biggest cause of their pregnancy is 'sexual violence' [13].

According to data published by Nicaragua's Institute of Legal Medicine, 9,069 cases of sexual violence occurred in 2013 ; in $88 \%$ of these, the victims were teenage girls. Especially in Nicaraguan tradition, girls who become pregnant before the age of 18 are regarded as adults, but even if they are, they cannot enjoy the practical benefits of being an adult, such as their rights to education, health, and protection and appropriate quality of life.

\section{2) Honduras}

Honduras has ranked 129th in the Human Development Index (HDI) among a total of 187 countries in the 2014 Human Development Report published by the United Nations Development Program (UNDP) [13]. According to the same data, Honduras is ranked 99th in the 2013 Gender Inequality Index. The main output index was 100 deaths per 100,000 (per 100,000) and 84 pregnant women under 19 (per 1,000). 
Despite these problems, Honduras is the only country in the world that has criminalized the emergency contraceptive pill and pushed a total ban on emergency contraceptive pills. The country ignored the rights of women and girls who were sexually assaulted and failed to provide birth control even in those circumstances [14]. In the end, the Honduran Supreme Court ruled that the use of the contraceptive pill was "abortion" and granted a law that completely prohibited post-emergence contraception.

As a result, post-birth control, a crucial means of preventing unwanted pregnancies, has been criminalized, and this has become another cause for the victim to be unable to prevent pregnancy. In particular, the Multidimensional Poverty Index of Honduras is $20.7 \%$, with $60 \%$ of its population living below of the national poverty line, with inequalities in education and health assessed to be severe. In other words, the restriction of educational opportunities according to income level is unfairly high, and in the health field, the proportion of medical expenses of low-income households per household income is much higher than that of the highincome earners. Nevertheless, the budget allocation ratio of government is very low.

\section{3) Ecuador}

J. Y. Oh's study shows that Ecuadorian women give birth to an average of 2.6 babies per person, which is similar to the global birth rate. However, the rate of teen pregnancy from 15 to 19 years was accounted for 77 per 1,000 mothers, which is approximately 1.5 times higher than the world average of 48.5. Like Nicaragua and Honduras, Ecuador has a poor education status. Although education up to the sixth grade of elementary school is mandatory, the actual enrollment rate in middle school is only $74 \%$. Nevertheless, delivery by medical personnel is as high as $91 \%$. However, unfortunately, the rate of infant mortality under 5 years old was high (23 cases per 1,000 births and maternity mortality rate was 87 cases per 100,000 births) due to the high pregnancy rate among juveniles.

\section{4) Guatemala}

In Guatemala, according to J. Y. Oh (2015), the average fertility rate per woman was 3.8, showing one more person than Ecuador, which we have seen before. In Guatemala, births by trained medical personnel are as low as 51\%, and the rate of youth pregnancy is 97 per 1,000 pregnant women, more than two times higher than the world average of 48.5 . The rate of infant mortality under 5 years old was low at 15 per 1,000 births, but due to teen pregnancy, the maternal mortality rate was 140 per 100,000 births. As in Nicaragua and Honduras, education status of Guatemala is inadequate. Even though, Guatemala has a compulsory education system up to grade 6 , the actual enrollment rate in middle school is only $46 \%$ and illiteracy rate is $44.4 \%$.

\section{5) El salvador}

J. Y. Oh continues explains in her study that women in El Salvador have a total fertility rate of 2.2 per capita, 0.7 times the world average. In Salvador, births by trained medical personnel accounted for $85 \%$, contraceptive use was $72 \%$, and $78 \%$ of mothers had received antenatal care more than four times were. The youth pregnancy rate was 76 per 1,000 mothers, 1.5 times the world average of 48.5. Largely driven by this situation, infant mortality rates under 5 years old were 22 per 1,000 births and maternal mortality rates were 69 per 100,000 births.
In El Salvador, abortion is being done secretly because of the existence of a repressive abortion law. If a woman is killed in an abortion or convicted after an abortion, she will be sentenced to up to eight years in prison. In addition, medical personnel who help with abortions are also being punished with up to 12 years in prison. Moreover, according to Amnesty International report (2014), in case of miscarriage, the aggravated punishment for murder is up to 50 years' imprisonment.

Amnesty International (2014) cited the El Salvador Health Authority report that 19,909 abortions were conducted between 2005 and 2008, and an average of $30 \%$ were on people under 17 years of age at the time of abortion. In particular, $57 \%$ of the deaths of pregnant women between the ages of 10 and 19 in El Salvador were reported as suicide, and more than 1,000 cases of female sexual assault have been reported to the police for a given year. Surprisingly, two-thirds of these victims were under the age of 15 or classified as having "mental retardation."

El Salvador is one of seven Latin American countries with legal prohibitions of abortion, along with Chile, the Dominican Republic, Haiti, Honduras, Nicaragua and Suriname. Some of these countries, such as Chile, are already in the process of revising their laws.

\section{6) Dominican republic}

According to the Korea Women's Development Institute(2014), the total population of the Dominican Republic is 9.4 million, with a youth population of 2.5 million, accounting for $25 \%$ of the total population; there, J. Y. Oh also mentions that $22.1 \%$ of adolescents aged 15 to 19 have at least one child. Thus, the Dominican Republic has the fifth highest teen pregnancy rate in Latin America, following Nicaragua, Honduras, Venezuela, and Ecuador.

The problem of teen pregnancy in the Dominican Republic is so serious that $30 \%$ of newborn babies are born from underage mothers, and $19 \%$ of mothers who die at birth are underage. In addition, $13 \%$ of teenagers aged 15 to 19 have experienced violence, and $7.5 \%$ have experienced sexual violence. Many teen pregnancies are the result of intimidation or child abuse. In addition, teen pregnancy increases the chances of producing poverty, AIDS, violence, drugs, accidents, suicide, school interruptions, premature infants, retarded children, and disabilities.

The Korea Women's Development Institute (2014) insists that the Dominican Republic's teen pregnancy problem is strongly correlated with poverty. The poverty rate in the Dominican Republic is on the rise, with $50 \%$ of the population aged 14-17 not attending school. Moreover, only $18.4 \%$ of students finish their studies. A striking 33.2\% of youth and young women in extreme poverty families have been pregnant before the age of 20 . The probability of a nonpregnant teens falling into poverty is $16 \%$, while that of a pregnant teen is $28 \%$. Finally, teen pregnancy is one of the biggest reasons why $44 \%$ of young people stop studying. Most of the girls usually drop out when they become pregnant, but the boys tend to continue their education.

\section{Discussions on Policy MeAsures to IMPRove MA- TERNAL AND CHILD HEALTH}

\section{A. Educational Perspective}

From an educational point of view, sex education is being 
actively considered as an effective method. Sex education is necessary to lead a worthy life in a human society composed of both sexes. It is based on understanding men's and women's characteristics and roles. Sexual education helps humans maintain good relationships with others and at the same time helps them form appropriate sexual consciousness, healthy sexuality, and sensible sexual habits. This allows humans to live a healthy life that matches prevalent lifestyle, cultural, and social norms. In addition, it helps to understand sexual characteristics and roles of both sexes, and to understand and accept each other as people with sexual desires and sexual behaviors, and to choose a spouse as a partner who can achieve a happy family life together [15].

It is also means of preventing sexual harassment and gives meaning to young people who are growing up [15]. In other words, since adolescence is a transition period in which people undergo physical, psychological, and socially unstable and diverse changes, adolescents typically lack the ability to make decisions or act as independent entities. Therefore, distorted expressions of sexuality that abound during this period can induce guilt and cause various problems. The majority of young people do not have the opportunity to get accurate knowledge or appropriate advice to resolve issues about their growing body, and their questions and concerns. Due to the overabundance of information on distorted sexuality, sexual derangement and sex offenses of teenagers are increasing, and sexual problems of teenagers are emerging.

During the period, when teenagers become more interested in sex, if they cannot properly distinguish sound information from harmful information and abstain from sexual desire, they can experience psychological anxiety or conflict and commit sex crimes. This can be a great obstacle to growth as a healthy adult, so it is important to cultivate the ability to solve the sexual problems of the young people themselves, and to protect themselves from sexual crimes [16].

According to J. Y. Oh (2015), the effects of sex education were diverse and positive First, by having information and knowledge about sex, adolescents are able to prevent having sexual intercourse due to curiosity. Second, sex offenses did not increase among those who received sex education. This means that sex crimes are more likely to be committed by people who lack information about sex. Third, after having sex education, adolescents become more responsible for their sexual activity.

However, despite the effects of sex education, most Latin American countries have shown low interest in sex education and a low enrollment rate. In a survey of youths in three Latin American countries, Ecuador, El Salvador, and Guatemala, Oh $(2015,12-13)$ found that the contents to be covered in school sex education were "pregnancy and contraception," "sexual violence and sex crimes," and "love and righteous heterosexualism." However, 74.3\% of the respondents did not receive such sex education at school. Oh surveyed the literature from the above-mentioned three countries in Latin America, but there was no proper guidance on school sex education. Although each school has its own sex education, there is no regular and systematic education.
Therefore, it is necessary to improve the sex education in schools in order to solve the problem of teen pregnancy. School sex education is an issue that the state should deal with from an educational policy standpoint. Therefore, the country should have a long-term plan for human rights and future generations. To this end, it is necessary to develop a sex education manual that reflects the current situation of each country in Latin America. Through this manual, teachers would be required to carry out sex education, and schools would have to prepare courses and standardized curricula so that universal sex education can be achieved. Most countries in Latin America do not have guidelines for school sex education because the state has not developed a sex education manual. Therefore, school sex education cannot be conducted consistently and uniformly. Moreover, even if sex education is provided, most of the adolescents do not receive sexual education because it is not obligatory.

\section{B. Plans from a National Policy and Welfare Perspective}

Among the Latin American countries, El Salvador, Chile, the Dominican Republic, Haiti, Honduras, Nicaragua, and Suriname currently ban abortion legally. Among them, Honduras is the only country in the world that has banned post-contraception (emergency contraception) treatments.

This is possible because these countries still have relatively poor awareness of women's human rights, ambiguous state policy on human rights, and lack welfare systems. Of course, not all politicians and citizens of these countries agree with this fact. In Honduras, in May 2009, the president vetoed the post-contraceptive bill because it contravened the Constitution. However, unfortunately, the Supreme Court opposed the veto. In addition, according to Amnesty International (2014), Chile is making efforts to amend the bill to allow abortion, and Nicaragua is committed to joining the Girl Power Project of the International Cooperation Agency to lower the pregnancy rates of teenage girls and protect their rights. In order for these efforts to be fruitful, politicians must make persistent efforts to revise the law and try to change the human rights awareness of women.

Socially, there is a need to jointly establish facilities for the safety and comfort of young pregnant mothers. In the case of El Salvador, although there are more than 1,000 reported cases of sexual violence a year, there is only one shelter for women, which accommodates only 35 people. Therefore, the rest of them are subject to imprisonment for illegal abortion. Even if you do give birth, this will lead to social burdens due to the increase in health, education, and economic costs. Therefore, it is necessary to cooperate with the community or neighbors to cope with the teen pregnancy problems. In addition, social co-operation and support are needed to provide a space where they can live together and solve each other's pain and hardship as well as giving birth to and raising their babies safely.

\section{Plans from an International Cooperation Perspective}

Teen pregnancy is a social and national problem that should not be regarded as solely a problem of the individual who is pregnant, and is recognized as a global health problem. H. S. Yoon $(2015,29-67)$ also pointed out that improvement of "awareness in the health sector is emerging as a way to ensure sustainability [of improvements in teen 
pregnancy rates] by providing knowledge and acting on the right health behaviors."

From an international cooperation point of view, the problem of teen pregnancy should be handled within the framework of health. From the viewpoint of development cooperation, basic health promotion projects such as the construction of hospitals and public health centers and the dispatch of volunteer groups have been underway as support for health projects.

Until now, only diseases caused by health risk behaviors such as smoking, drinking, eating habits and lack of exercise have been regarded as non-communicable diseases and attention has been focused on them. However, solving the teen pregnancy problems should also be set as a major goal in the field of health care in terms of international cooperation from the viewpoint of social cost and burden reduction and prevention.

In particular, the WHO (2013) pointed out that active interventions are needed because social costs of noncommunicable diseases in developing countries have exceeded funding levels. In developing countries, noncommunicable diseases have increased rapidly since 2000 and the importance of smoking, drinking, hypertension, and obesity management is emphasized. In addition, according to H. S. Yoon (2015), the WHO has set a goal of $25 \%$ reduction in premature death from non-communicable diseases by 2025 , and the UN is discussing ways to reduce socioeconomic costs due to non-communicable diseases.

From now on, more attention should be paid to teen pregnancy problems in Latin American countries, and efforts should be made to reduce socioeconomic costs and mortality caused by adolescent pregnancies. Moreover, since teen pregnancy in Latin American countries is related to poverty and education, we need a development cooperation strategy in Latin America. In other words, to solve social inequality, it is necessary to establish a strategy to help the poor grow, to improve and expand social infrastructure, and to propose and spread a success model centered on the base area.

In addition, the characteristics of medical services in Central and South America are such that segmentation is severe. In addition, medical insurance and public health services are not provided properly, and patients do not have the necessary services. Therefore, the international community must cooperate to improve the quality of backward medical facilities and services in Latin American countries. In addition, it is urgently necessary to make efforts to solve problems in the community by means of alliances of Latin American countries. This is because the teen pregnancy and maternal and child health problems are common issues throughout Latin American countries. Therefore, a longterm plan approaching from the concept of a regional community in all Latin American countries should be established.

\section{CONCLUSION}

This study was carried out in order to review the current state of maternal and child health and related policy measures. In particular, the maternal and child health situation in Latin America is very serious due to the problem of teen pregnancy and childbirth. In general, the problem of teen pregnancy and childbirth does not end with the problems of the individual adolescents but causes various social costs and burdens. As a result, we no longer regard teen pregnancy and childbirth as personal problems, but as social problems of global significance.

As a result of examining the status of teen pregnancy in Latin America, countries such as Nicaragua, Honduras, Ecuador, Guatemala, El Salvador and Dominican Republic showed of the most serious teen pregnancy problem. In these countries, teen pregnancy rates are increasing day by day, along with infant mortality rate and maternal mortality rate. Notably, all of these countries have poverty and low education levels in common.

Therefore, we have learned that solving the problem of poverty and low education level is indispensable to prevent and manage teen pregnancy problems in these countries. This study has highlighted that there is a need to look at the problem of teen pregnancy in the following three dimensions.

First, we have to solve the problem of teen pregnancy from the viewpoint of education. In other words, it is necessary to improve school sex education. Sex education helps improve understanding sexual characteristics and roles of men and women in general and allows young people to understand themselves as being able to have sexual desires and sexual behaviors. In addition, sex education has a role to play in guiding individuals to a happy family life by choosing the right spouse. Considering that the education level of most countries in Latin America is low and there is no formal guidance on school sex education, it is necessary to improve the school sex education. To this end, we need to develop a sex education manual that reflects the current situation of each country, and teachers should conduct sexual education in accordance with this manual. Schools should prepare courses and curricula to enforce sex education.

Second, the perception of female human rights in Latin American countries was very low. Abortion and postpartum contraception (emergency contraception) are prohibited, so there is a limit to society's ability to deal with teen pregnancy and childbirth caused by rape. In some countries, efforts are being made to revise the law and to supplement the system, but little progress has been made. Efforts to improve these policies and institutions should be more actively pursued in each country. In addition, in view of the youth pregnancy rates in these countries, it is necessary to provide community facilities that enable teen or unmarried pregnant women to be safe and hygienic, to nurture their babies, and to survive independently.

Third, the problem of teen pregnancy in Latin America is no longer a problem only for Latin American countries. Currently, from the viewpoint of health policy, basic health promotion projects such as establishment of hospitals and public health centers, dispatch of volunteers, and so on, are under way as support for health projects. The teen pregnancy problem should also be treated within the framework of health. At present, the WHO emphasizes that noncommunicable diseases in Latin America and other developing countries are causing high social and economic costs, and that the international community needs to actively intervene to solve this problem. Teen pregnancy and child- 
birth are also social problems that cause socioeconomic burdens. Therefore, the international community should consider this issue as a non-communicable disease and actively treat it as a major goal in the health field. Accordingly, it is necessary for the international community to pay great attention to the social problems of pregnancy and childbirth of Latin American youth and to support the healthcare business.

This study examined the status of maternal and child health, and the problem of teen pregnancy, in Latin American countries. Due to lack of data and research in this area, it was difficult to conduct comprehensive research. Moreover, there are some countries that are worse off than the ones discussed in this paper. Therefore, further studies will need to be conducted on the various countries of Latin America and developing countries outside Latin America.

\section{REFERENCES}

[1] H. H. Kim, "A study on pregnancy and childbirth experience of Adolescent unmarried mothers," M.A. thesis, Graduate School of Sookmyung Women's University, 2014.

[2] E. G. Park, "A Survey on the maternal and child health services in public health centers: Focused on Daejeon metropolitan city," M.A. thesis, Graduate School of Management and Administration, Daejeon University, 2000.

[3] World Health Organization (WHO). "Global status report on noncommunicable diseases," 2010 World Health Organization "10 facts about diabetes", 2013.

[4] H. J. Kim and S. N. Yoon, Community Nursing, 6th ed. Seoul: Sumunsa, 1998.

[5] T. G. Park, Mother and Child Health, Seoul: Yonsei University Press, 1982.

[6] M. H. Yoon, "A study on the factors related to pregnancy and infant adoption of teen unmarried mothers," M.A. thesis, Graduate School of Sookmyung Women's University, 2000.
[7] S. No, "A qualitative study on the process and experience of becoming a single maternity," M.A. thesis, Chonnam National University Graduate School, 2002.

[8] K. S. Jung, "Pregnancy and Childbirth Experience of Teenager Unmarried Mothers," Journal of Korean Academy of Child Health Nursing, vol. 14, no. 2, pp. 186-194, 2008.

[9] J. Y. Oh, "Comparative Analysis of Sexuality and Sexual Behavior for Establishing Teaching Strategies for Teaching Sexual Education in Latin America and America," M.A. thesis, Chungbuk National University, 2015.

[10] United Nations Population Fund (UNFPA). World Po Pulation Report (Korean version), 2013.

[11] Rio Korea. (November 4, 2008). [Online]. Available: http://riokorea.kr/index.php? code $=$ NSBR $\&$ mode $=$ view $\&$ num $=9155 \&$ page $=70$

[12] Korea Women's Development Institute, Report on the Post-mortem Evaluation of Maternal and Child Health in Four Latin American Countries, Seoul: Korea International Cooperation Agency, 2014.

[13] Plan Korea Committee. (Aug. 13, 2015). Nicaragua: the highest teen pregnancy rate in Latin America. [Online]. Available: http://www.plankorea.or.kr/news/news/view/4327?q=Because+I+am $+\mathrm{a}+$ Girl\&categories $=\& \mathrm{t}=$

[14] Amnesty International. (April 29, 2014). [Online]. Available: www.amnesty.or.kr/9803.

[15] H. S. Yoon, "A study on post-2015 health projects in Latin America with improved recognition," Ibero America, vol. 17, no. 2, pp. 29-67, 2015.

[16] M. H. Lee, "A study on sexual consciousness, sexuality and sex education in urban youth," Journal of Korean Home Economics Education, vol. 6, no. 2, pp. 41-58, 1994.

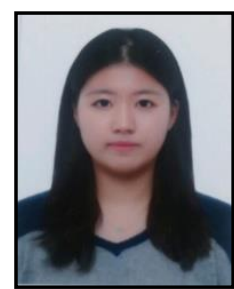

Sung Hyun Park was born in Seoul, Korea. S. H. Park is currently enrolled in the 3rd year of Hankuk Academy of Foreign Studies. She is preparing to go to medical school in Korea next year. 